\author{
Onderzoeksrapport $\mathrm{Nr} .8215$ \\ PROTECTIVE STOCKS IN MULTI-STAGE \\ PRODUCTION SYSTEMS \\ by \\ MarC R. LAMBRECHT ${ }^{*}$ \\ John A. MUCKSTADT: \\ Robert LUYTENE
}

Wettelijk Depot : D/1982/2376/24

* Katholieke Universiteit Leuven, Dep. of Applied Economics

- School of Operations Research and Industrial Engineering, Cornell University.

This report was published as Technical Report No. 562, School of Operations Research and Industrial Engineering, Cornell University.

This research was supported in part by the National Science Foundation under grant MSF-81-21429 and by the onderzoeksfonds K.U. Leuven under grant $\mathrm{OT} / \mathrm{IX} / 7$. 



\section{MTOUCr IOH}

Hatertal Requirembets planhing (MRp) Systons have been developed durling the past two decates to provide a mechan in for coordinating the replentshent of components, subassublies, and find products in mult astage production and dstribution systens. The MRp rystems used in practice are based on the assumption that all factors affecting production are know wh centanty over a product's total manufacturing

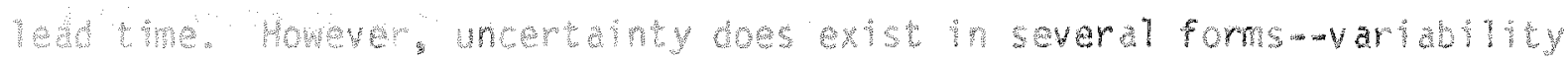
in denan from pertod to pertod. uncertatrity the supply from stage to stage due to the vathblity in the yields prom each production batch. and uncertatnty th the lead times for both production and procurenent. Protecthon agatnst the disuptions in protucton caused by these sources of uncertatity 's reculped, however, au orten results in buffer stocks. These stock can duts as sarety stock or as imventory resulting fron the

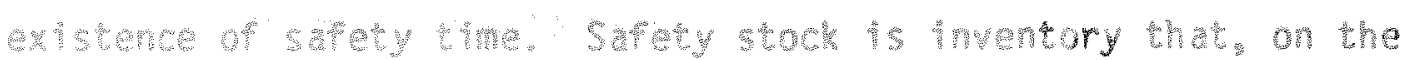
average, always axiston. It Is the expected anount of on-hand inventory at a stage Just before production of a lot is avallable or a procurentent order arrives at that stage. Roughly speaking, safety time occurs when a probution batch or procurement lot becomes avallable before it is needed to produce sone subsequent ussenbly or finished product.

Safery stock is paeded to protact against uncartainties in the

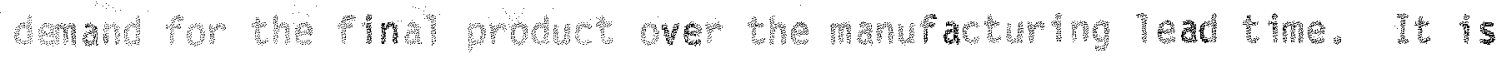

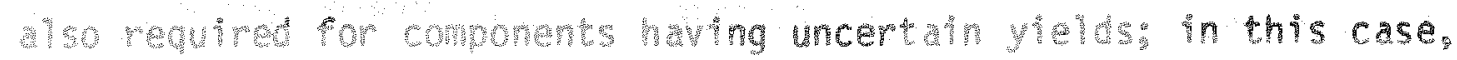
safaty stock preserves lot stae integrty and keeps the number of setups from growing. particularly at botheneck work conters. Findly. safery stock may be deshable for components whinuthite uses. In case the 
components and assembltes are produced at regular intervals (cyctica) production schedules). safety stock may be desirable so that the manufacturing lead trimes for the assemblies using the components are maintaned at or near their nominal values.

Safety tine, on the other hand, usually exists when production and/or procurement lead times are uncertain; but, it may exist to protect against demand variability, as we wh subsequently observe.

In a practical situation, however, the origin of protective stocks may be difficult to determine. We will exanine some relatively simple problens in this paper for which we can neasure safety stock and safety time. As we will see, it is impossible to determine their values by simply examining the fom of the policy being followed.

Academic researchers have recogoined the need to create buffer stocks of the bypes we have mentioned while many practitionars do not admit that such stocks are necessary at internediate stages of production. Research to date has produced no results that provide a fundamental understanding of the nature of protective stocks. In fact. the behavior of MRP derived policies is largely not understood much less the form and characteristics of optimal policies. Research on protective stocks in multi-stage systems has primarily been experimental. Simulaton models have been used to evaluate the effects of varlous policies on service levels and inventory investment in very special environments. The work to BANERJEE [2] and WHYBARK and WILLIAPS [13] are Illustrations of this approach. MRP folklore nomally suggests protecting against uncertainty by creating safety stock of final products. MLLER [10] suggests an alternative to this policy. He 
recormends the utilization of a pipeline" safety stock strategy that is based on the recognition of the dependent demand relationships between final products and intermediate stages and the value added cost structure. His hedging strategy is designed to keep safety stocks in the supply pipeline rather than in the stockroon in finished product form. CARLSON and YANO [3] [4] also developed a methodology to tack le the safety stock probien. Their approach is primarily experimental. They conclude for a special situation that finished product safety stocks are in general more appropriate than intermediate level safety stocks. NEW [1] critically reviews the existing uncertainty protection mechanisms in avallable MRP systems. MEAL [9] developed a statistical method for determining the proper time to produce at each stage.

As we have said, it is oum opinion that these research efforts have provided linited insight into when. why or how much safety stock and safety time should exist in multi-stage production systems. Furthemore. this research has produced no computationally feasible approaches for computing operating policies for even slightly complex systems. In this paper it is our goal to address these issues for situations in which denand variablity is the sole source of uncertainty. To achieve this goul, we have organized the remainder of the paper as follows.

In Section II, we develop a mathenatical model-a dynamic programing model--that can be used to find an optimal operating policy for multi-stage systems when denand is the only source of uncertainty, the plaming horizon is finte and a periodic review policy is followed. We next show how this problem can be viewed as a Markovian Decision Problen (Mop). In Section III we show that the exact methods developed in 
Section II are of limited practical value and review the well known results of CLARK and SCARF $[5,6]$ for analyzing serial systems. We indicate how their method can be modified to obtain solutions for assenbly type systems.

In Section IV we present results of an experiment. The form and nature of the operating policies are discussed. In particular, we show that generalized $(5,5)$ policies appear to be optimal. The experiment shows that the modified Clark-Scarf approach, which also yields policies of the ( $s, s)$ type, provides excellent results. The computational results indicate that both safety time and stock can exist at intermediate stages. Examples are presented lllustrating the presence of safety time and stock.

In Section $V$ we analyze the form the policies obtained when following Mrp logic. Specifically. we observe that the policy followed using MRP logic is an $(s, 5)$ policy. As such, both safety stock and time can exist when the denand for the final products is uncertain. This occurs, as we show with an example, even though their existence is not anticipated when establishing the production schedule. We conclude that the $(5,5)$ policies generated using MRP logic will perform wells in an expected cost sense, when lead times and demand variability per period are relatively iow. 


\section{I1. MODEL FORMULATION}

In this section we present two modelling approaches. First, we show how to fomulate the multi-stage production planning problem as a dynamic programing problem when the time horizon is finite. Second, we show that the problen can be modelled as a Markovian Decision Problem. Attention in this case is limited to the situation where the demand process is stationary and the planning horizon is infinite; however, the same observation can be made for a finite horizon as well. The models we present are based on the following assumptions:

1. The product structures are known:

2. A periodic review policy is followed;

3. The production and procurement lead times, which are measured in periods, are known constants,

4. The demand distributions are known; denand is independent from periodetomeriod for each final product:

5. All excess demand for final products is backordered. We also assume that the relevant costs consist of production costs, at each stage, which are composed of a fixed setup cost per production run and a constant cost per unit produced, hoiding costs, which are charged proportional to the echelon stock at the end of a period, and linear shortage costs. which are charged proportional to the number of units of final product back ordered at the end of each period. 


\section{A. A Dynamic Programming Formulation}

The multi-stage production planning problem we have discussed can be formulated as a dynamic programming problem. The formulation we give is appropriate when the planning horizon is finite and when each item is either a final product or component, but not both. The formulation can be eastly modified to accommodate situations in which itens $c$ an be both final products, say spare parts, as well as a component for a higher level assembly. The nodel also allows production capacity to be taken into account. As we will show, the formulation is quite complicated and hence, except for relatively simple problems is computationally intractable. This is due to the size of the state space. For this problem, the state of the system reflects the number of units an-hand for each item and the number of units thataill become available for use in each time period as a consequence of previous production decisions. Thus, if lead times are long and/or the number of values that can be assumed by the state variables is large, the state space set can consist of an enormous number of elenents.

We will use the following nomenclature in the dynamic programming model. Let

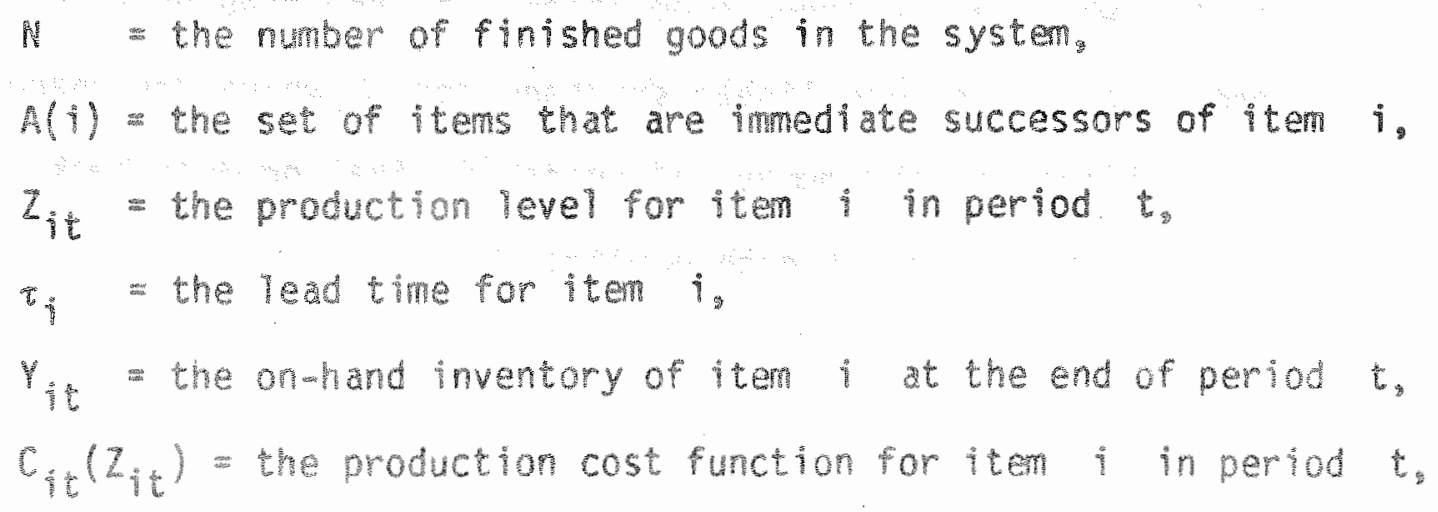




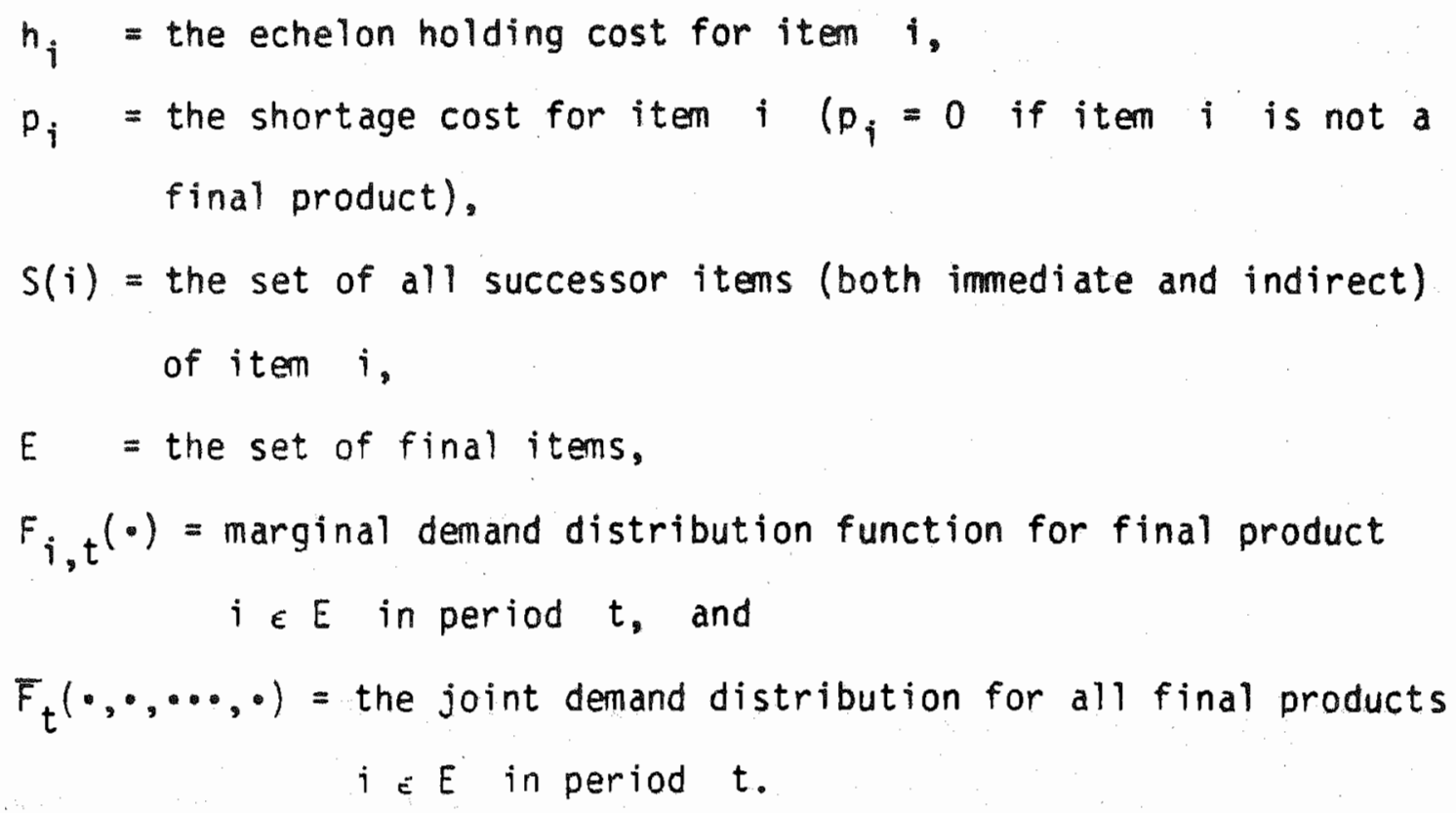

Let $f_{n}(\cdot)$ represent the minimum expected cost of operating the system assuming $n$ periods remain in the planning horizon. Time periods are numbered to reflect the number of periods remaining in the planning horizon, as illustrated as follows.
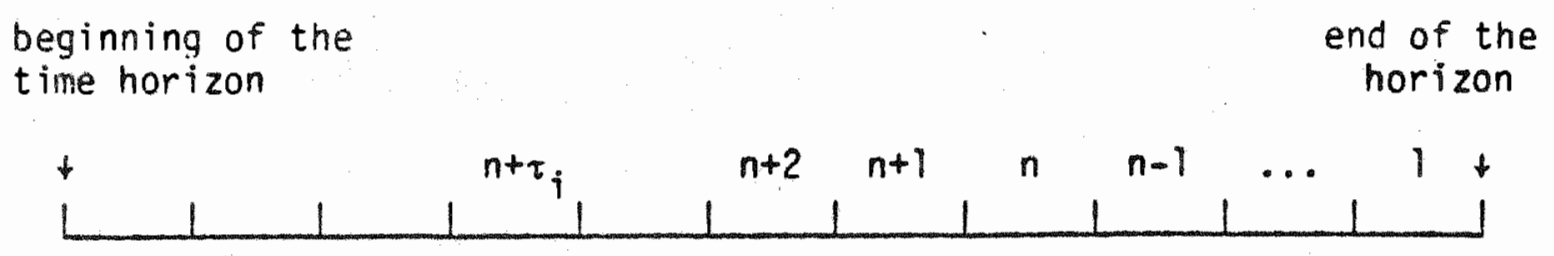

To reduce the difficulty of writing the argument for the function $f$, we simply use $\left(\gamma_{i, n}, z_{i, n} \ldots, z_{i, n+\tau_{i}-1}\right)$ to represent the state of the system for all items at the beginning of period $n$ following the production decision for that period. Then 


$$
\begin{aligned}
& \operatorname{li}_{n}\left(Y_{i, n+1}, z_{i, n+1} \ldots z_{i, n+z_{i}}\right)= \\
& \min _{z_{i n}>0}\left(c_{i} c_{i n}\left(z_{i n}\right)\right. \\
& z_{i n} e p \quad \text { (production costs) }
\end{aligned}
$$$$
+\sum_{i q E}\left(n_{i}\left(Y_{i, n+1}+z_{i, n+\tau_{i}}{ }_{j \in A} \sum_{(i)} Z_{j n}\right)\right.
$$$$
\text { (holding costs for units of component i on-hand) }
$$

$$
\begin{gathered}
+j \in S(i)-E n s(i) h_{i}\left(Y_{j, n+1}+\sum_{l=0}^{\tau_{i}} z_{j, n+l}-\sum_{k \in A(j)} z_{k n}\right) \\
\begin{array}{c}
\text { (holding costs for units of } i \text { in units of successor items } \\
\text { that are not finished goods) }
\end{array}
\end{gathered}
$$

$$
\left.{ }_{j \in S(i) n E}\left[h_{i}\left(\int_{0}^{\max \left(0, Y_{j, n+1}+z_{j, n+\tau_{j}}\right)}=\left(Y_{j, n+1}+z_{j, n+\tau_{j}}-u\right) d F_{j n}(u)+\sum_{2=0}^{\tau_{j}-1} z_{j, n+l}\right)\right\}\right] \mid
$$

(holding costs for units of $i$ in finished items in production or on-hand)

$$
\begin{aligned}
& +\sum_{i \in E}\left(p _ { i } \operatorname { m a x } \left(0, y_{i, n+1} \int_{i, n+\tau_{i}}^{\infty}\left(u-\left(y_{i, n+1}+z_{i, n+\tau_{i}}\right)\right) d F_{i n}(u)+\right.\right. \\
& \left.h_{i} \max \left(0, Y_{i, n+1}^{+z_{i}, n+\tau_{i}}\right)\left(Y_{i, n+1}+z_{i, n+\tau_{i}}-u\right) d F_{i n}(u)\right\}
\end{aligned}
$$

(penalty costs for shortage + holding costs for finished items)

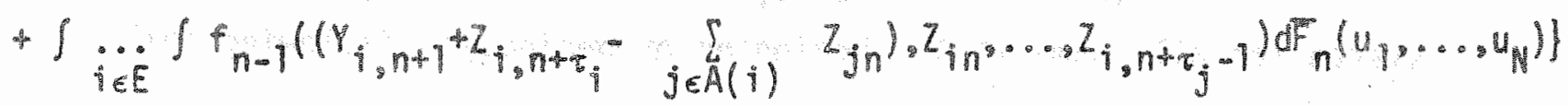

$$
\begin{aligned}
& U_{i} \text { if } i \in E
\end{aligned}
$$


where $p$ is the set of constraints reflecting lead time and production restrictions for each iten in each period.

The problen is solved beginning at the end of the horizon and working backwards until the beginning of the horizon is reached. The dynamic programing formulation is based on the echelon-stock concept. The echelon stock for facility i equals the installation stock at that faclity plus the on-hand stock position at all succeeding facilities. As a consequence, the echeion holding costs reflect the value added structure. The characterization of optimal solutions is given in terms of echelon stock.

\subsection{Markovian Decision Processes (MDP)}

When the denand process is statlonary, the costs are time independent and the planning horizon is infinite, the dynamic programming problem introduced in Section II. A can be viewed and modeled as a Markovian Decision Process problem, as we whl now see. The systen is observed at sime $t=0,1,2, \ldots$ and classfified into one of a finite number of states, where, as before, the states represent on-hand plus on-order inventory for each stage. For every state i a number of decision alternatives, $k$, is possible, labeled $1,2, \ldots, k(i)$. Whenever the system is in state $i$ and decision $k$ is made, the system moves to a new state $j$. with known transition probability $p_{i j}^{k}$ which is detemined based on the demand distribution. Let $a_{i}^{k}$, represent the expected cost incurred when the systen is in state $i$ and decision $k$ is made.

The transition probabilities are time imvariant since the denand distribution is stationary. Thus the process of moving from 
state-to-state is a Markov process. Furthermore, since the expected costs, $q_{i}^{k}$ and the transition probabilities, $p_{i j}^{k}$ depend on the decision that is made, the model has the form of a Markovian Decision process. Consequentiy, the solution can be obtained using the successive approximation procedure developed by HOWARO [7]. This is clearly preferable to using a standard dynamic programing approach for solving the problem. However, due to the size of the state space, even this method is of little practical value.

\section{I.C. Cmments Concerning the Preceding Formulations}

In the preceding subsections we showed that the problem of detemining the optimal production plan for each stage can be formulated as a dynamic progran, and when the demend process and costs are time independent, as a MDP. We repeat that the state space in either formulation grows rapidly as the lead time and number of demand possibilities in each period increase. Thus these models are of little practical use; however, they are of considerable value for testing the quality of the solutions obtained using heuristics, which is how we shall use then. 


\section{II. A HEURISTIC: A MODIFIED CLARR AND SCARF APPROXIMATION PROCEDURE}

Since the exact methods for finding an optimal solution to the multimstage production planning problen presented in Section II are computationally intractable for most realistic problens, it is necessary to develop an alternative method for finding good, if not optimal, solutions. In this section we suggest such a procedure. However, we limit our attention to assembly or serial type systems, such as displayed in figure 1. By an assembly system, we mean a product structure in which each iten has at most one successor item, but any number of predecessors. We will use the numbering of stages as given in figure 1: namely, stage 1 is the final stage and stage $M$ is the beginning stage.

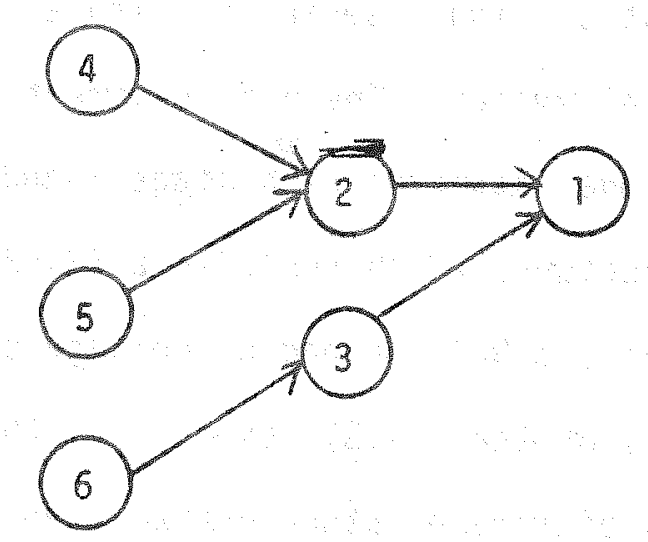

Stage 3 Stage 2 Stage 1

FIGURE 1a: A Three Stage Assembly System

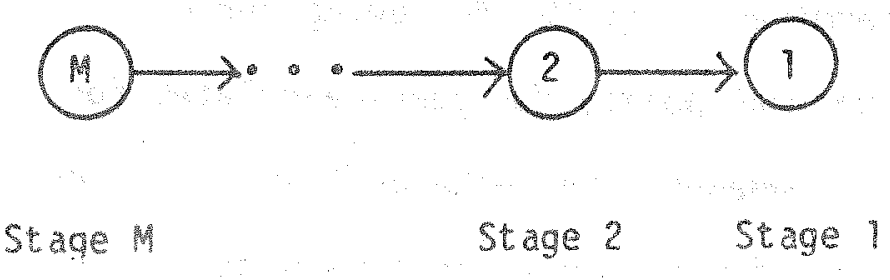

Flgure 1b: An M Stage Serial System 
The procedure we suggest is a modification of one developed by CLARK and SCARF [6]. We adapt their approach for solving serial system problems to the more general assembly system problems. Since our heuristic is based on the Clark and Scarf approximation, we begin this section by reviewing it.

\section{III.A. The Clark and Scarf Approximation}

The methods described in Section II are computationally intractable because the state space becomes too large to solve problems of a practical size. The $\mathrm{Clark}$ and Scarf approximation circumvents this problem. Rather than solving the problen for all stages simultaneously, Clark and Scarf suggest solving a series of simpler problems, one for each stage in the serial system. The replenishment policy is computed separately for each stage, starting with stage 1 and ending with stage M. Given the cost structure, which includes a fixed setup cost, a variable production cost, a holding and a shortage cost, the optimal policy at each stage is of the $(5,5)$ type [1]. The optimal policy is always stated in terms of echelon stock rather than installation stock.

The shortage costs used when finding the myopic policy for stages 2 through $M$ are not specified explicitly in advance. Rather, they measure the additional costs at subsequent stages that are incurred due to the policy followed at a given stage. For example, the imputed cost at stage 2 is determined using the following logic.

Suppose the optimal policy has been calculated for stage 1. The solution states that whenever the echelon 1 stock is less than $s_{7}$, production is started for an amount sufficient to bring the echelon 1 
stock up to $S_{y}$, where $s_{j}$ and $S_{j}$ are the policy variables for echelon j. However, the echelon stock for stage 2 may not always be of sufficient size to raise stage I's echelon stock to $S_{p}$. When it isn't, an additional cost is incurred at stage 1 . since stage 1 is no longer following its optimal policy. The expectation of these resulting incremental costs for stage 1 is the imputed shortage or penalty cost function for stage 2. The penalty functions for the remaining stages can be calculated in a similar fashion. We subsequently present the mathenatical details that implement these notions.

The Clark and Scarf concept for decomposing the complex production problen does not always find the optimal policy. When the fixed setup cost is zero for stages 1 through $M-1$, they show that the solution is optimal. However, when the fixed setost is positive for any of the stages 1 through $M-1$, then the computed policy may not be optimal $[5,6]$. In the latter case, they suggest an approximation method that yields upper and lower bound estimates on total cost.

We present the details for the Clark and Scarf approximation procedure for a two stage serial system. We show how calculations are made for stage 1 followed by those for stage 2. The procedure can easily be extended to any number of stages.

\section{a. Computation for stage 1}

The following steps are used to detemine the locally optimal $(\$, S)$ policy for stage I. As we did earlier time periods are numbered to refiect the number of periods ranining in the horizon. The algorithm for this stage consists of three steps. which we now present. 
Step 1: Calculate $g_{1, n}(y)$ for all $y$ and 1 et $S_{1, n}$ be the value of $y$ that solves the problem

$$
\min _{y}\left[q_{1}, n(y)\right]=\min _{y}\left[c_{1, n}(y)+L_{1, n}(y)+\sum_{q=0}^{\infty} f_{1, n-1}(y-q) p_{n}(q)\right] \text {, where }
$$

$g_{1, n}(y)=$ the minimum expected cost for stage 1 for period $n$ through the end of the horizon (period 1).

$c_{\eta, n}(y)=$ the cost of producing $y$ units for arrival at time $n=x_{1}$. $p_{n}(q)=$ the probability distribution (discrete distribution) of demand for period $n_{s}$ and

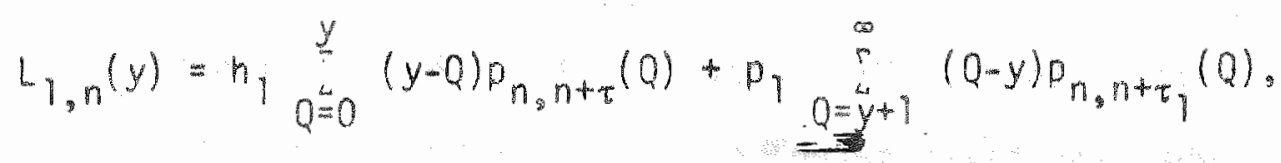

where $q$ is the demand for periods $n$ through $n-\tau_{p}\left(0=q_{n}+\ldots+q_{n-\tau}\right)$.

Step 2: Let $s_{1}$, be the smallest value for which

$$
9, n\left(s_{1, n}\right) \leq 9, n(5, n)+k_{1}
$$

where $k_{q}$ is the setup cost for stage 1 .

Step 3: Calculate $f_{1, n}\left(x_{1, n}\right)$ for all $x_{1, n}$, where $x_{1}, n$ is the Imventory on wand and on-order at the begiming of pertod $n$.

$$
f_{\eta_{n}, n}\left(x_{1, n}\right)= \begin{cases}L_{1, n}\left(x_{1, n}\right)+\sum_{q} f_{1, n-1}\left(x_{1, n}-q\right) p_{n}(q), & x_{1, n} \geq s_{1, n} \\ k_{1}+c_{1, n}\left(s_{1, n}-x_{1, n}\right)+L_{1, n}\left(s_{1, n}\right)+\sum_{q} f_{1, n-1}\left(s_{1, n}-q\right) p_{n}(q), & x_{1, n}<s_{1, n}\end{cases}
$$

${ }^{8}, 0^{(\circ)}=0$, 
The procedure obviously starts at $n=1$ and proceeds backwards. Given the fixed charge cost structure, there is an optimal policy of the $\left(s_{1, n}, s_{1, n}\right)$ type: furthermore, if $k_{1}=0, s_{1, n}=s_{1, n}$.

\section{b. Computation for Stage 2}

In this subsection we show how to computate stage 2's lacally optimal $(5,5)$ policy. To minimize notational difficulties, we assume a zero lead time at stage 2. The three step procedure is as follows.

Step : Calculate $\overline{9}_{2, n}(y)$ for all $y$ and let $S_{2, n}$ be the value of y that solves the probiem

$$
\min _{y}\left[\bar{g}_{2, n}(y)\right]=\min _{y}\left[c_{2, n}(y)+L_{2, n}(y)+\sum_{q=0}^{\infty} f_{2, n-1}(y-q) p_{n}(q)\right] .
$$

The expected holding and shortage cost function $\tau_{2, n}(y)$ includes a penalty function $\Lambda(y)$. Rather than using the exact function $\Lambda(y)$. clark and Scarf propose bounding it. The upper bound function $\bar{A}_{n}(y)$ is obtained by charging an additional shortage cost whenever the echelon stock $\left(x_{2, n}\right)$ for stage 2, is less than $S_{1, n}$ (even in cases where the stage 1 order point is not reached). The lower bound, $\Lambda_{n}(y)$ is defined to be different from zero only when $x_{2, n} \leq s_{1, n}$

We have chosen to use $\bar{\Lambda}_{n}(y)$ in our calculations of $L_{2, n}(y)$. $\vec{A}_{n}(y)$ is obtained as follows. When the on-hand and on-order inventory at stage $1, x_{1}, n$ is less than $s, n$, an order is placed of size $\left(s_{1}, n^{-x_{1}}, n\right)$. Then the expected minimum cost would be

$$
k_{1}+c_{1, n}\left(s_{1, n}-x_{1, n}\right)+L_{1, n}\left(s_{1, n}\right)+\sum_{q} f_{1, n-1}\left(s_{1, n}-q\right) p_{n}(q) .
$$


But, if $x_{2, n}<s_{1, n}$ we will not be able to order up to $S_{\eta}, n$, in which case we are restricted to order up to $x_{2, n}$. Then the stage 1 expected cost is

$k_{1}+c_{q, n}\left(y-x_{1, n}\right)+L_{1, n}(y)+\sum_{q}^{n} f_{1, n-1}(y-q) p_{n}(q)$, where we let $y=x_{2, n}$.

$\bar{A}_{n}(y)$ is defined as the difference between (2) and (1) when $y<s_{1, n}$ and 0 otherwise; that is,

$$
\bar{\Lambda}_{n}(y)=\left\{\begin{array}{cc}
0 & , y \geq s_{1, n} \\
c_{1, n}\left(y-s_{1, n}\right)+L_{1, n}(y)-L_{1, n}\left(s_{1, n}\right)+ & \\
\hdashline\left[f_{1, n-1}(y-q)-f_{1, n-1}\left(s_{1, n}-q\right)\right] p_{n}(q), & y<s_{1, n} \\
& =0
\end{array}\right.
$$

and, therefore.

$$
L_{2, n}(y)=n_{2} \sum_{0=0}^{y}(y-Q) p_{n, n+\tau}(q)+\bar{A}_{n}(y) .
$$

The final two steps of the procedure are as follows.

Step 2: Let $s_{2, n}$ be the smallest value for which

$$
\bar{g}_{2, n}\left(s_{2, n}\right) \leq \bar{g}_{2, n}\left(s_{2, n}\right)+k_{2}
$$


Step 3: Calculate $f_{2, n}\left(x_{2, n}\right)$, for all $x_{2, n}$, where $x_{2, n}$ is the echelon stock for stage 2, and

$$
f_{2, n}\left(x_{2, n}\right)=\left\{\begin{array}{c}
L_{2, n}\left(x_{2, n}\right)+\sum_{q} f_{2, n-1}\left(x_{2, n}-q\right) p_{n}(q), x_{2, n} \geq s_{2, n} \\
k_{2}+c_{2, n}\left(s_{2, n}-x_{2, n}\right)+E_{2, n}\left(s_{2, n}\right)+ \\
\\
\sum_{q} f_{2, n-1}\left(s_{2, n}-q\right) p_{n}(q), x_{2, n}<s_{2, n}
\end{array}\right.
$$

c. Observations Concerning the Clark and Scarf Approximation Procedure

There are several important observaions we have made concerning the behavior of the Clark and Scarf approximation orocedure.

As we have seen, the policy values are calculated independently from stage-to-stage. This is the method'smajor computational advantage over the algorithms we presented in Section II. Unfortunately, the policy variables must sometimes be adjusted to reflect the interactions anong the stages. For example, in a two stage system. the policy at stage 2 is determined independently of that found for stage i; however, the replenishment policy at stage 1 depends on the echelon stock for stage 2. In other words, $\left(s_{1, n}, s_{1, n}\right)$ depends on $x_{2, n}$ as we now illustrate.

Suppose in period $n$ that the control parameters for stage 1 are given by $s_{1, n}=3$ and $s_{1, n}=5$ and the graph of $g_{1, n}(y)$ is as shown in Figure 2. Suppose $x_{2, n} \geq s_{1, n}$ Then the control parameters shown in Figure 2 remain unchanged $\left(s_{1, n}=3\right.$ and $\left.s_{1, n}=5\right)$. If, however, $x_{2, n}<S_{1} n$. We recompute the control parameters in the following way. Set the new order-up-to level, say $S_{1, n}$ equal to $x_{2, n}$ and detemine the 


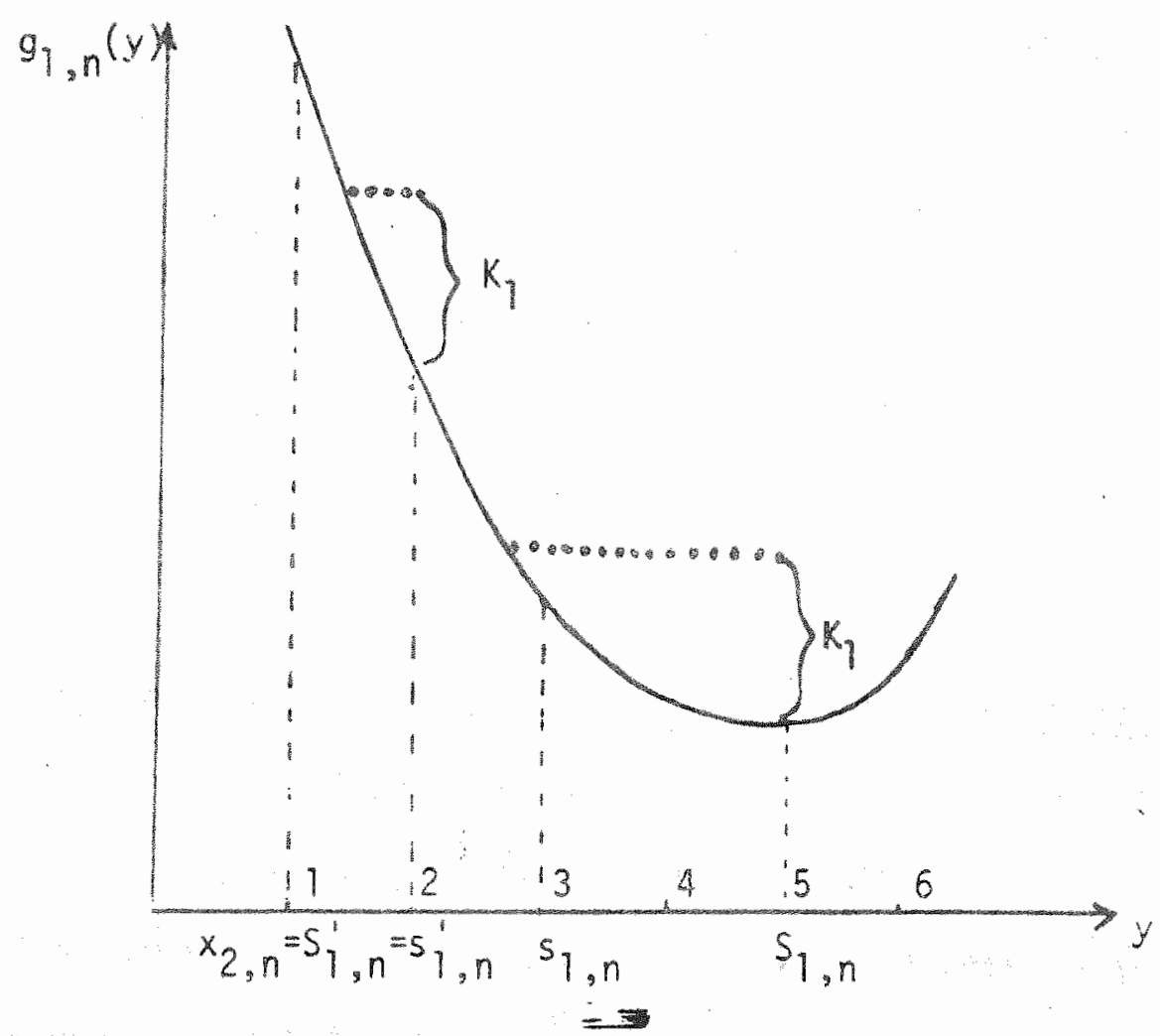

FlGURE 2. Graph of $9_{1, n}(y)$

corresponding $s^{i}, n$ to be the smallest value for which

$$
\begin{aligned}
9_{1, n}\left(s_{1, n}^{\prime}\right) \leq 9_{1, n}\left(s_{1, n}^{\prime}\right)+k_{1}, \text { where } \\
\qquad s_{1, n}^{1}=x_{2, n}
\end{aligned}
$$

In Figure 2, we see that $s_{1, n}^{1}=2$ and $s_{1, n}^{\prime}=2$, if $x_{2, n}=2$. In general, can conclude that the control paraneters at stage 1 are functions of $x_{2}, n$. We call policies in which such modifications are made generalized $(s, s)$ policies. Thus the solutions generated by the clark and Scarf procedure may need to be modified in certain cases if an optimal policy is to be followed. 
Our computational experiments have also identified a major weakness in the clark and Scarf algorithm when the cost structure is such that the setup-to-holding cost ratios for successive stages satisfy $\frac{k_{j}}{h_{j}}<\frac{k_{s}(j)}{h_{s}(j)}$, where $s(j)$ represents the successor stage to stage $j$. We illustrate the potential problems using the following examples.

Suppose demand in each period is for either 0,1 , or 2 units of the final product with probabilities of $.25, .50$, and .25 , respectively. Furthermore, assume the production lead time for stage 1 is one period and for stage 2 is 0 periods. We study three examples, whose cost data are given in Table I.

\begin{tabular}{|c|c|c|c|c|}
\hline Example & Iten & $k_{j}$ & $n_{i}$ & $p_{1}$ \\
\hline 1 & 1 & 50 & 1 & $50 / 100 / 200$ \\
& 2 & 1 & 10 & \\
\hline 2 & 1 & 4 & 4 & $100 / 200 / 400$ \\
& 2 & 40 & 5 & \\
\hline 3 & 1 & 50 & 1 & $50 / 100 / 200$ \\
\hline & 10 & 5 & \\
\hline
\end{tabular}

TABLE 1. Data for Example Problems 
Examples 1 and 2 are each two stage serjal systems whereas Example 3 is a two stage assembly system whose structure is shown in figure 3.

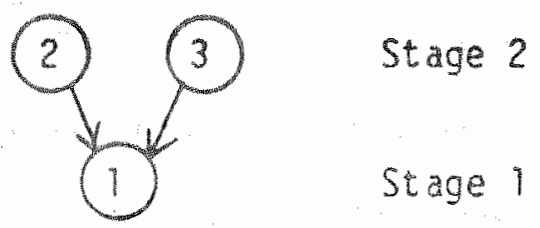

FIGURE 3. Assembly Structure for Example 3.

Let's exanine the setup to holding cost structure for these three examples. For Example 1.

$$
\frac{k_{2}}{h_{2}}=\frac{1}{10}<\frac{50}{1}=\frac{k_{1}}{h_{1}}
$$

for Example 2,

$$
\frac{k_{2}}{h_{2}}=\frac{40}{5}>\frac{4}{4}=\frac{k_{1}}{h_{1}}
$$

and for Example 3 .

$$
\left.\begin{array}{l}
\frac{k_{2}}{h_{2}}=\frac{1}{10} \\
\frac{k_{3}}{h_{3}}=\frac{10}{5}
\end{array}\right\}<\frac{50}{1}=\frac{k_{1}}{h_{1}} .
$$

In a deteministic situation. for cost structures that correspond to Examples 1 and 3 , the lot sizes for all itens should be identical, as shown by hamell 
and Muckstadt [8] and others. Thus the production for these items should be planned to occur simultaneously when demand occurs continuously and at a constant rate. For Example 2, the lot size for stage 2 will be greater than that for stage 1 , since $\frac{k_{2}}{h_{2}}>\frac{k_{1}}{h_{1}}$. These observations are essentially the result of using the economic lot size formula to calculate production quantities. This observation should be a guide to identifying reasonable policies for probabilistic demand problems. Namely, in serial or assembly type systems we should generally have $s_{j}-s_{j} \geq s_{s(j)}-s_{s(j)}$. Otherwise, several production lots may be produced for item $j$ per lot of $s(j)$. In cases where the production lot for item $j$ exceeds $S_{j^{-s}}{ }_{j}$, it is possible to have $s_{s(j)}{ }^{-s_{s}}(j) \leq s_{j}-s_{j}$. However, the actual production lot sizes will normally correspond to the relationship suggested by the solution to the related deteministic problen.

The solutions found using the MDP and the Clark and Scarf methods for these three examples are given in Tables II-IV. We see that the Clark and Scarf method obtains the wrong solution for Examples 1 and 3 . Furthermore, the annual costs obtained when following the Clark and Scarf approach are substantially greater than the optimal cost for Examples 1 and 3 . This occurs because the policies found using the Clark and Scarf method are not coordinated when they are determined. This occurred for all other examples we evaluated where the natural lot size (EOQ lot size found using echelon holding costs) for item 1 is greater than that for iten 2 . We also found that the Clark and Scarf solutions are normally optimal or extremely close to being optimal (well within $1 \%$ of the optimal average annual cost) when the natural lot sizes are in the right order, as they are in Example 2. Observe that the optimal value of $S_{1}{ }^{-S_{1}}$ is smaller than 


\begin{tabular}{|c|c|c|c|c|c|c|}
\hline \multirow{3}{*}{ Item } & \multicolumn{6}{|c|}{ Shortage Costs } \\
\hline & \multicolumn{2}{|c|}{50} & \multicolumn{2}{|c|}{100} & \multicolumn{2}{|c|}{200} \\
\hline & $\begin{array}{c}C S \\
S^{\circ} N\end{array}$ & $\begin{array}{l}O P T \\
S O L ' N\end{array}$ & $\begin{array}{c}C S \\
S O L^{\prime} N\end{array}$ & $\begin{array}{c}O P T \\
\text { SOL'N }\end{array}$ & $\begin{array}{c}C S \\
S O L^{\prime} N\end{array}$ & $\begin{array}{l}O P T \\
\text { SOL'N }\end{array}$ \\
\hline 2 & $(3,3)$ & $(2,5)$ & $(4,4)$ & $(3,5)$ & $(4,4)$ & $(3,5)$ \\
\hline 1 & $(3,12)$ & $(2,5)$ & $(3,12)$ & $(3,5)$ & $(4,13)$ & $(3,5)$ \\
\hline
\end{tabular}

TABLE II. Policies for Example I

\begin{tabular}{|c|c|c|c|c|c|c|}
\hline \multirow{3}{*}{ Iten } & \multicolumn{6}{|c|}{ Shortage Costs } \\
\hline & \multicolumn{2}{|c|}{100} & \multicolumn{2}{|c|}{200} & \multicolumn{2}{|c|}{400} \\
\hline & $\begin{array}{c}C S \\
\text { SOL'N }\end{array}$ & $\begin{array}{l}\text { OPT } \\
\text { SOL'N }\end{array}$ & $\begin{array}{c}C S \\
\text { SOL'N }\end{array}$ & $\begin{array}{l}\text { OPT } \\
\text { SOL N }\end{array}$ & $\begin{array}{c}C S \\
\text { SOL' } \mathrm{N}\end{array}$ & $\begin{array}{l}O P T \\
S O L^{\prime} N\end{array}$ \\
\hline 2 & $(3,6)$ & $(3,6)$ & $(3,6)$ & $(3,6)$ & $(4,7)$ & $(4,7)$ \\
\hline 1 & $(3,4)$ & $(3,4)$ & $(3,4)$ & $(3,4)$ & $(4,4)$ & $(4,4)$ \\
\hline
\end{tabular}

TABLE III. Policies for Example 2

\begin{tabular}{|c|c|c|c|c|c|c|}
\hline \multirow{3}{*}{ Iten } & \multicolumn{6}{|c|}{ Shortage Costs } \\
\hline & \multicolumn{2}{|c|}{50} & \multicolumn{2}{|c|}{100} & \multicolumn{2}{|c|}{200} \\
\hline & $\begin{array}{c}C S \\
\text { COL'N }\end{array}$ & $\begin{array}{l}\text { OPT } \\
\text { SOL'N }\end{array}$ & $\begin{array}{c}C S \\
\text { SOL }\end{array}$ & $\begin{array}{c}\text { OPT } \\
\text { SOL'N }\end{array}$ & $\begin{array}{c}\text { CS } \\
\text { SOL'N }\end{array}$ & $\begin{array}{c}\text { OPT } \\
\text { SOL'N }\end{array}$ \\
\hline 3 & $(4,9)$ & $(2,4)$ & $(5,9)$ & $(2,5)$ & $(6,9)$ & $(3,5)$ \\
\hline 2 & $(3,3)$ & $(2,4)$ & $(4,4)$ & $(2,5)$ & $(4,4)$ & $(3,5)$ \\
\hline 1 & $(3,12)$ & $(2,4)$ & $(4,13)$ & $(2,5)$ & $(4,13)$ & $(3,5)$ \\
\hline
\end{tabular}

TABLE IV. Policies for Example 3 
the Clark and Scarf method for Examples 1 and 3 while $S_{2}-S_{2}$ is greater. The reason that the optima! policies are identical for each stage is that the lead times are 0 for stage 2 itens. This need not be the case when $\tau_{2}>0$. Our observations concerning the performance of the Clark and Scarf approximation procedure suggests that some modifications should be made to improve its performance.

11.B. A Modified Clark and Scarf Algorithm for Assembly Systems

Modifications to the Clark and Scarf algorithm that rectify some of the oroblems we observed are presented in this section. We first discuss how the algorithm can be extended to obtain solutions to problems having assembly type product structures.

That the Clark and Scarf approximation algorith can be easily extended to assembly type systems should not be surprising. Let us illustrate how this can be done for a two stage assembly system, such as the one for Example 3 shown in Figure 3. First, obtain a locally optimal solution for stage 1, using the method discussed in Section III.A.a. Once this solution is obtained, calculate the penalty function and separately apply the method described in Section III.A.b to components 2 and 3.

Obviously this approach can be extended to any assembly system. We note that this extension possesses the shortcomings we discussed for the Clark and Scarf algorith plus an additional one. We pointed out that by separately calculating policies for each item we can obtain policies, in certain cases. that are not coordinated. This can obviously happen for the extension we have described. However, it can occur in an additional way as well.

Again consider Example 3. If the control policies calculated for components two and three are not coordinated, then it may be the case that 
there are a large number of units on hand for component 2 but none for component 3 thereby making it impossible to produce any units of iten 1. Thus the implementation of the $(s, s)$ policies at stage 2 must be modified to account for what we call horizontal interaction. The following example illustrates this need for coordination. The data for the example are given in Table $V$. The denand distribution is the sane as for Examples 1-3. The optimal solution is given in Table VI. As can be seen from Table VI, the replenishment control paraneters for iten 1 depend on the minimum of $x_{2}$ and $x_{3}$, the echelon stock for components 2 and 3 , respectively. This obviously results in the desired coordination.

\begin{tabular}{|c|c|c|c|}
\hline Iten & $k_{i}$ & $n_{i}$ & $p_{i}$ \\
\hline 1 & 10 & 2.7 & 500 \\
2 & 25 & 1.26 & \\
\hline 3 & 25 & 2.52 & \\
\hline
\end{tabular}

TABLE V: Data for Example 4

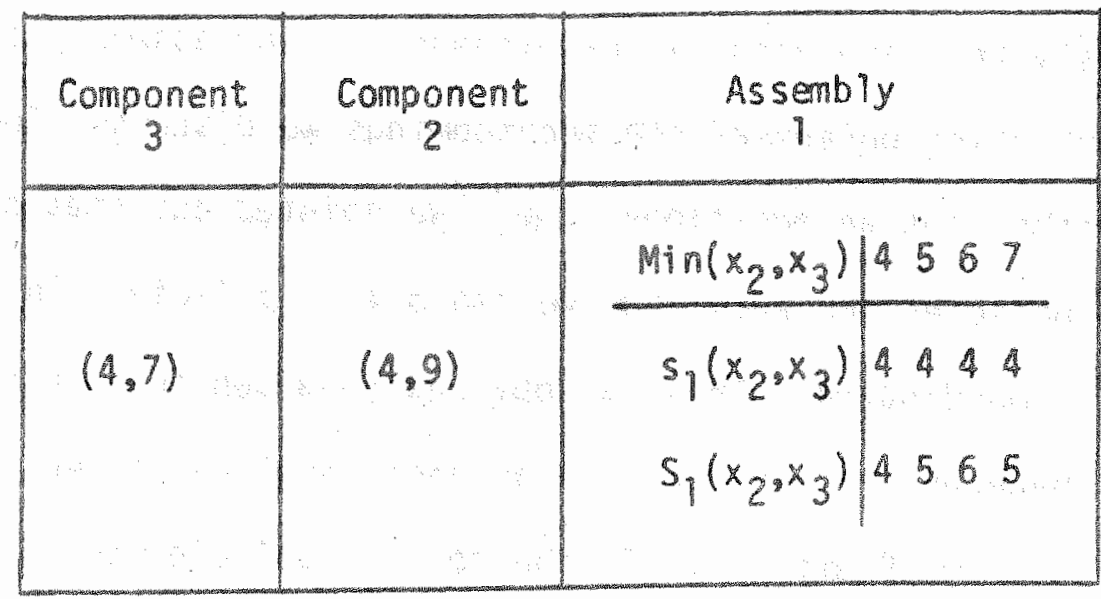

TABLE VI: Optima! Solution for Example 4 . 
The modification we propose to the Clark and Scarf algorithm pertains to the coordination problem we observed in serial structures when $\frac{k_{j}}{h_{j}}<\frac{k_{s}(j)}{n_{s(j)}}$. The modification will be explained for a two stage serial system. Extensions to other serial or assembly systems can be accomplished in a straightforward manner. We call this heuristic, the modified Clark and Scarf (MCS) procedure.

\section{MCS Procedure}

Step 1: If $\frac{k_{j}}{h_{j}} \geq \frac{k_{s}(j)}{h_{s(j)}}$, then compute the operating policies as described in section III.A, that is, using the method suggested originally by clark and Scarf. Otherwise, go to step 2.

Step 2: If $\tau_{2} \leq 1 / 2 \tau_{1}$, go to step 3; otherwise, go to step 4.

Step 3: Collapse the problem into a single stage problem and apply clark and Scart's procedure for this resultina single stage problem. As a consequence both stages will follow the same replenishment pollcy.

(The set-up cost and the holding cost for the collapsed problem are respectively given by $k_{1}+k_{2}$ and $h_{1}+h_{2}$. The lead time is given by $\left.\tau_{1}+\tau_{2}\right)$

Step A: Compute the replenishment policy for each stage separately. a. Stage 2 policy: Collapse the two stage problen into a single stage problen and obtain the common replenishment policy. Use the resulting policy for stage 2. (The set-up cost and holding costs used when finding the policy are $k_{1}+k_{2}$ and $h_{1}+h_{2}$, respectively.) 
b. Stage 1 policy: Use Clark and Scarf's procedure with parameters $k_{1}, h_{1}$ and $p_{q}$ to obtain the policy at stage?.

Our computational experiments suggest that when $\tau_{2}$ is low relative to $\tau_{T}$, it is generally better, in terms of expected costs, to implement the collapsed policy instead of computing the policies separately for each stage. We therefore have suggested that the collapsed policy be used when $\tau_{2} \leq 1 / 2 \tau_{1}$. We point out that additional experimentation is needed to identify the conditions under which step 3 or Step 4 should be selected. Dur limited experience suggests that $\tau_{2} \leq 1 / 2 \tau_{1}$ works well; however, we have no proof that this policy is the best possible one.

We comment that the optinal solutions for Examples 1 and 3 are found when using the proposed MCS procedure. 


\section{IU. EXPERIMENTAL RESULTS}

He conducted an experiment to achieve two goals. Our first objective was to compare the solutions obtained using the MCs procedure with optimal solutions. Thus our goal is to identify when the MCS works well. The second goal was to find conditions under which safety stock and safety time exist. As we have pointed out previously, the amount of safety stock and time that exist are a function of the policy that is followed. Consequently, it is not surprising that our experiments show that under certain circumstances both safety time and stock should exist.

\section{IV.A. The Experiment}

Optimal policies and those found using the MCS procedure were calculated for a number of lead time, denand distrubution, and cost combinations. In all cases, a two stage serial production system was exanined. Thus this experiment obviously does not allow us to make general statements conceming the potential usefulness of the MCS algorithm for solving more complicated problens. However, the results indicate that such an approach, or some further modification of it. may very well be a good heuristic to use to obtain cost effective operating policles for more complex product structures.

The cost structures we used in the experiment are given in Table VII. The fixed production costs $\left(k_{i}\right)$, the echeion holding costs $\left(h_{i}\right)$, and the finished product shortage cost $\left(p_{1}\right)$ are given for two structures. In the fipst case, $\frac{k_{2}}{h_{2}}=1<6-\frac{k_{1}}{h_{1}}$, and in the second case $\frac{k_{2}}{h_{2}}=6>1=\frac{k_{1}}{h_{1}}$. Thus the modification we made to the Clark and Scarf algorithm will be important in all cases where the first cost structure is used.

Two denand distributions for the final product are used in the experiment. The expected demand is the same for both distributions; however. 
the variance is higher for the second distribution. The specification of these distributions is given in Table VIII.

\begin{tabular}{|c|ccc|ccc|}
\hline \multirow{2}{*}{ Stage } & \multicolumn{3}{|c|}{ Structure 1 } & \multicolumn{3}{|c|}{ Structure 2 } \\
\cline { 2 - 7 } & $k_{i}$ & $h_{i}$ & $p_{1}$ & $k_{i}$ & $h_{i}$ & $p_{1}$ \\
\hline 1 & 30 & 5 & 150 & 9 & 9 & 150 \\
2 & 9 & 9 & $\ldots$ & 30 & 5 & $\ldots$ \\
\hline
\end{tabular}

TABLE VII. Cost Data for the Experiment

\begin{tabular}{|c|c|c|c|}
\hline \multicolumn{2}{|c|}{ Denand Distribution A } & \multicolumn{2}{|c|}{ Demand Distribution B } \\
\hline $\begin{array}{c}\text { Demand Per } \\
\text { Period }\end{array}$ & Probability & $\begin{array}{c}\text { Denand Per } \\
\text { Period }\end{array}$ & Probability \\
\hline 0 & 0 & 0 & .4 \\
7 & .4 & 1 & 0 \\
2 & .3 & 2 & .1 \\
3 & .2 & 3 & .2 \\
4 & .1 & 4 & \\
\hline Mean $=2$ & Mean $=2$ & \\
Variance $=1$ & Variance $=3$ \\
\hline
\end{tabular}

TABLE VIII. Demand Distributions for the Experiment

One of the most important factors affecting the values of the poricy parmeters, and hence the anount of safety stock and time, is the lead time. The lead time conbinations given in Table IX were used in the experiment. These values, measured in periods, were selected to determine the effect on the selection of an operating policy when the relative lead time lengths differ between the two stages. As can be expected, these differences significanty change the values of the policy parameters. 


\begin{tabular}{|c|c|c|}
\hline $\begin{array}{c}\text { Lead Time } \\
\text { Combination }\end{array}$ & For Stage 1 $\left(\tau_{1}\right)$ & Load Stage 2 $\left(\tau_{2}\right)$ \\
\hline 1 & 1 & 0 \\
2 & 1 & 1 \\
3 & 2 & 1 \\
4 & 1 & 5 \\
5 & 5 & 1 \\
\hline
\end{tabular}

TABLE IX. Lead Time Combinations Used in the Experiment

Twenty problems were constructed using various combinations of the cost structures, demand distributions and lead time values given in Tables VII-IX. Table $x$ gives the exact specification of each of these problems. The solutions for these problens are given in Table XI. In each case, the operating policies are stated in terms of echelon stock. For problems $1-12$ we give both the solutions obtained using the MCS procedure and the optimal solution. We did not determine the optimal policy for problems 13-20 because the state space was too large for each of the corresponding MDPs. We note that the time required to find the solutions differed substantially. The solutions obtained using the MCS procedure were calculated in a few seconds using an Apple 111 computer while the optimal solutions were obtained in several minutes on an IRH 370-168.

The solutions found using the Mcs procedure were virtully the same as the optimal solution for 8 of the 12 problems. The expected cost per period for the MCS procedure was within. $5 \%$ of the optimun for 11 of the 12 problems and was within $1.8 \%$ of the optimum on the remaining problem. Thus it appears that the MCs procedure provides a reasonable method for calculating operating 


\begin{tabular}{|c|c|c|c|}
\hline $\begin{array}{l}\text { Problem } \\
\text { Number }\end{array}$ & $\begin{array}{c}\text { Cost } \\
\text { Structure }\end{array}$ & $\begin{array}{l}\text { Demand } \\
\text { Distribution }\end{array}$ & $\begin{array}{l}\text { Lead Time } \\
\text { Combination }\end{array}$ \\
\hline 1 & 2 & $A$ & 1 \\
\hline 2 & 2 & $B$ & 1 \\
\hline 3 & 1 & A & 1 \\
\hline 4 & 1 & $B$ & 1 \\
\hline 5 & 2 & $A$ & 2 \\
\hline 6 & 2 & $B$ & 2 \\
\hline 7 & 1 & $A$ & 2 \\
\hline 8 & 1 & B & 2 \\
\hline 9 & 2 & $A$ & 3 \\
\hline 10 & 2 & $B$ & 3 \\
\hline 11 & 1 & $\div$ & 3 \\
\hline 12 & 1 & $B$ & 3 \\
\hline 13 & 2 & A & 4 \\
\hline 14 & 2 & $B$ & 4 \\
\hline 15 & $i$ & $A$ & 4 \\
\hline 16 & 1 & $B$ & 4 \\
\hline 17 & 2 & A & 5 \\
\hline 18 & 2 & $B$ & 5 \\
\hline 19 & $y$ & A & 5 \\
\hline 20 & 1 & $B$ & 5 \\
\hline
\end{tabular}

TABLEX: Specification of the Problems Used in the Experiment 


\begin{tabular}{|c|c|c|c|c|c|c|}
\hline \multirow[t]{2}{*}{$\begin{array}{l}\text { Problen } \\
\text { Number }\end{array}$} & \multicolumn{3}{|c|}{$\begin{array}{l}\text { Policy Found } \\
\text { Using Mcs }\end{array}$} & \multicolumn{3}{|c|}{$\begin{array}{l}\text { Optimal } \\
\text { Policy }\end{array}$} \\
\hline & $\begin{array}{l}\text { First } \\
\text { stage } \\
\text { policy }\end{array}$ & $\begin{array}{l}\text { Second } \\
\text { Stage } \\
\text { oticy }\end{array}$ & $\begin{array}{c}\text { Expected } \\
\text { Cost Per } \\
\text { Period }\end{array}$ & $\begin{array}{l}\text { First } \\
\text { Stage } \\
\text { Policy }\end{array}$ & $\begin{array}{l}\text { Second } \\
\text { Stage } \\
\text { policy }\end{array}$ & $\begin{array}{l}\text { Expected } \\
\text { Cost Per } \\
\text { Period }\end{array}$ \\
\hline 1 & $(6,7)$ & $(5,9)$ & 74.06 & $(6,7)$ & $(5,9)$ & 74.06 \\
\hline 2 & $(7,8)$ & $(7,11)$ & 88.288 & $(7,8)$ & $\begin{array}{l}\text { If } x_{1}=6,(6,11) \\
\text { If } x_{1} \neq 6,(7,71)\end{array}$ & 88.282 \\
\hline 3 & $(5,7)$ & $(5,7)$ & 82.55 & $(5,7)$ & $(5,7)$ & 82.55 \\
\hline 4 & $(6,8)$ & $(6,8)$ & 97.09 & $(6,8)$ & $(6,8)$ & 97.09 \\
\hline 5 & $(6,7)$ & $(8,12)$ & 79.07 & $(6,7)$ & $(7,12)$ & 79.01 \\
\hline 6 & $(7.8)$ & $(10,14)$ & 95.47 & $(8,8)$ & $(10,14)$ & 95.45 \\
\hline 9 & $(6.90)$ & $(7,10)$ & 90.124 & $(6,9)$ & $(7,10)$ & 90.122 \\
\hline 8 & $(7,8)$ & $(9,11)$ & 113.09 & $(7,11)$ & $(9,11)$ & 111.09 \\
\hline 9 & $(0,9)$ & $(10.14)$ & 96.22 & $\begin{array}{l}x_{2}=10,(8,9) \\
x_{2}=0,(9.10)\end{array}$ & $(10,14)$ & 95.75 \\
\hline 10 & $(10,11)$ & $(12,16)$ & 121.55 & $\begin{array}{c}x_{2}=12,(10,11) \\
x_{2}=12,(10,12)\end{array}$ & $(12,16)$ & 121.33 \\
\hline 11 & $(10,12)$ & $(10,12)$ & 114.80 & $(10,12)$ & $(10,12)$ & 114.80 \\
\hline 12 & $(11,14)$ & $(11,14)$ & 143.50 & $(11,12)$ & $\begin{array}{l}x_{1}=10,(11,14) \\
x_{1}=10,(11,15)\end{array}$ & 143.12 \\
\hline 13 & $(6.7)$ & $(17,21)$ & 87.317 & $\infty+\infty$ & $-\infty$ & $\infty$ \\
\hline$\sqrt{1}$ & $(7,8)$ & $(20,24)$ & 113.095 & $-\infty$ & -- & $-\infty$ \\
\hline 15 & $(6.70)$ & $(16.19)$ & 108.35 & $-\infty$ & $-\infty$ & $-\infty$ \\
\hline 16 & $(7.8)$ & $(18.22)$ & 144.40 & $\infty$ & $=\infty$ & $-m$ \\
\hline 17 & $(15,17)$ & $(17,21)$ & 141.80 & $-\infty$ & $-\infty$ & $-\infty$ \\
\hline 18 & $(18.19)$ & $(19.23)$ & 179.40 & $\infty$ & - & $-\infty$ \\
\hline 19 & $(16,99)$ & $(16,19)$ & 181.10 & $\rightarrow$ & $-\infty$ & $-\infty$ \\
\hline 20 & $(18,22)$ & $(18,22)$ & 222.90 & $\infty$ & $-\infty$ & $\infty x$ \\
\hline
\end{tabular}


policies for two stage serial systems. Furthermore, it is our opinion that this method will find very good operating policies for more complicated situations. Although we have not proven this, it appears that the optimal policy is always a generalized $(s, s)$ policy and is often a simple $(s, s)$ policy at each stage. Thus the policy produced by the Mcs method is the correct or close to the correct form.

The operating policies found depend on several factors. First, observe that in all cases as the variability in the demand process increases, the reorder point at each stage is strictly increasing. Thus additional protection is needed as the denand variability increases. Furthermore, the expected cost per period increases as well.

Second, we see that the expected cost is always lower for the second cost structure when comparing the solutions obtained based on cost structure 2. With those found using cost structure 1. Recall that cost structure $2^{\prime} 5$ costs differ from those in structure 1 only in that the setup and holding costs are reversed. The result is due in part to the fact that holding costs are higher for structure 1. It is also attributable to the fact that lot sizes at stage 1 are higher on the average in cost structure 1 than they are in structure 2 .

Third, we see that the lead time structure has a substantial affect on the values of the policy variables. Clearly as the lead times increase both the values of the policy variables and the expected costs increase. An interesting result is obtained when comparing lead time structures 4 and 5 . Note that the total lead time is 6 periods in each of these lead time structures. However, when the longer lead time is in the second stage, the expected costs are always correspondingly higher. 


\section{IV.B. Safety Time and Safety Stock}

Our final observations are related to the existence and amount of safety time and safety stock. It is impossible to determine the exact amount of safety stock or time by knowing only the values of the policy variables. We estimated these quantities for each problen using the policies given in Table $X I$.

Recall that safety stock is the expected amount of on hand inventory at the time an order or lot arrives. Note that safety stock can exist at either stage. Safety time exists only at stage 2. It measures the expected time between the completion of a lot at stage 2 until any units from that lot are used in the production of a lot at stage 1. When computing safety time, we assume stage 2 production lots are used in a FIFO manner by stage 1.

Using the operating policy comput using the MCS procedure for problen 6. we illustrate how the safety stock and time can be calculated. The policies are $(7,8)$ and $(10,14)$ for stages 1 and 2, respectively. Recall that these policies are stated in tems of echelon stock. The lead time is one period for each stage. The behavior of echelon and installation stock at each stage over a 52 period horizon is given in Figure 4 . The beginning on hand inventory at stage 1 is 8 and at stage 2 is 6 . The demands for the horizon, which were generated randomly from distribution 8 , are given in Table XII.

\begin{tabular}{|c|c|c|c|c|c|c|c|c|c|c|c|c|c|c|c|c|c|c|c|c|c|c|c|c|c|}
\hline Period & 1 & 2 & 3 & 4 & 5 & 6 & 7 & 8 & 9 & 10 & 11 & 12 & 13 & 14 & 15 & 16 & 17 & 18 & 19 & 20 & 21 & 22 & 23 & 24 & $25: i$ \\
\hline Demand & 0 & 4 & 0 & 0 & 4 & 2 & 2 & 0 & 3 & 3 & 0 & 0 & 4 & 4 & 0 & 0 & 3 & 0 & 3 & 0 & 0 & 4 & 3 & 4 & 0 \\
\hline Period & 27 & 28 & 29 & 30 & 31 & 32 & 33 & 34 & 35 & 36 & 37 & 38 & 39 & 40 & 41 & 42 & 43 & 44 & 45 & 46 & 47 & 48 & 49 & 50 & $51: 5$ \\
\hline Demand & 3 & 4 & 4 & 3 & 4 & 2 & 0 & 0 & 0 & 0 & 4 & 4 & 4 & 3 & 0 & 0 & 3 & 4 & 4 & 4 & 2 & 4 & 4 & 0 & 4 \\
\hline
\end{tabular}

TABLE XII. Demand Dat Generated From Distribution B for 52 Periods 
(a) On-Hand

Stock at

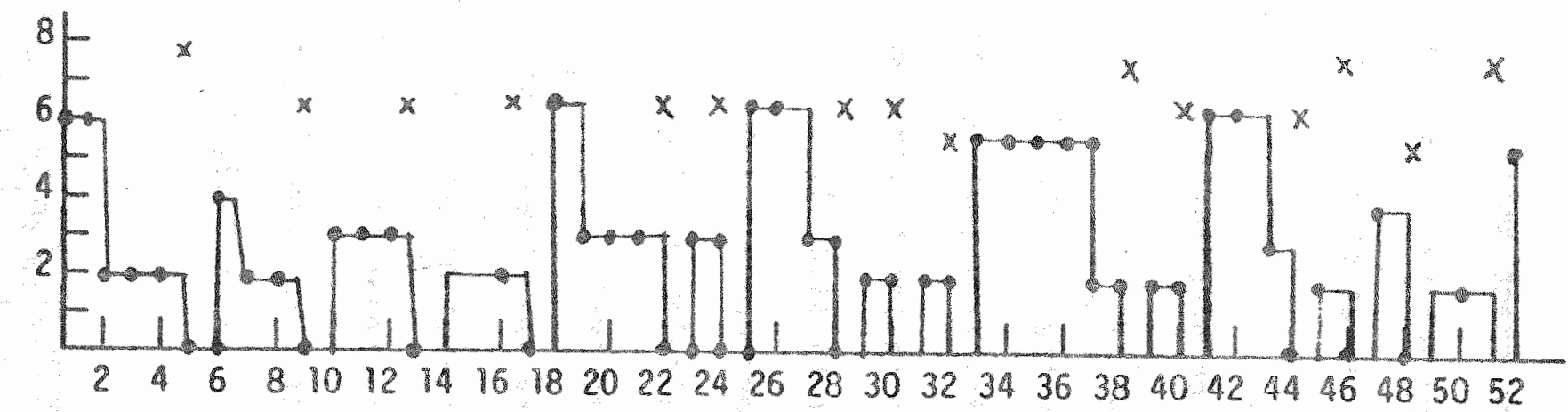

(b) Echeion

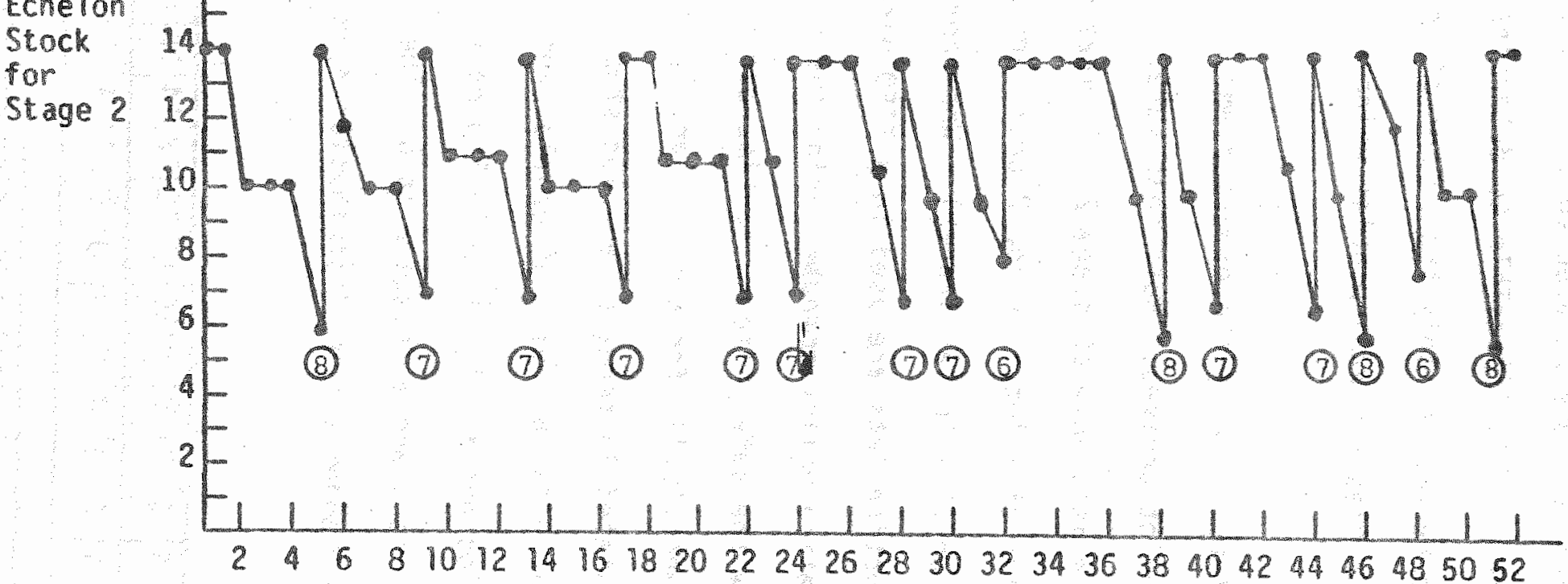

(c) On-Hand Stock

for

Stage 7

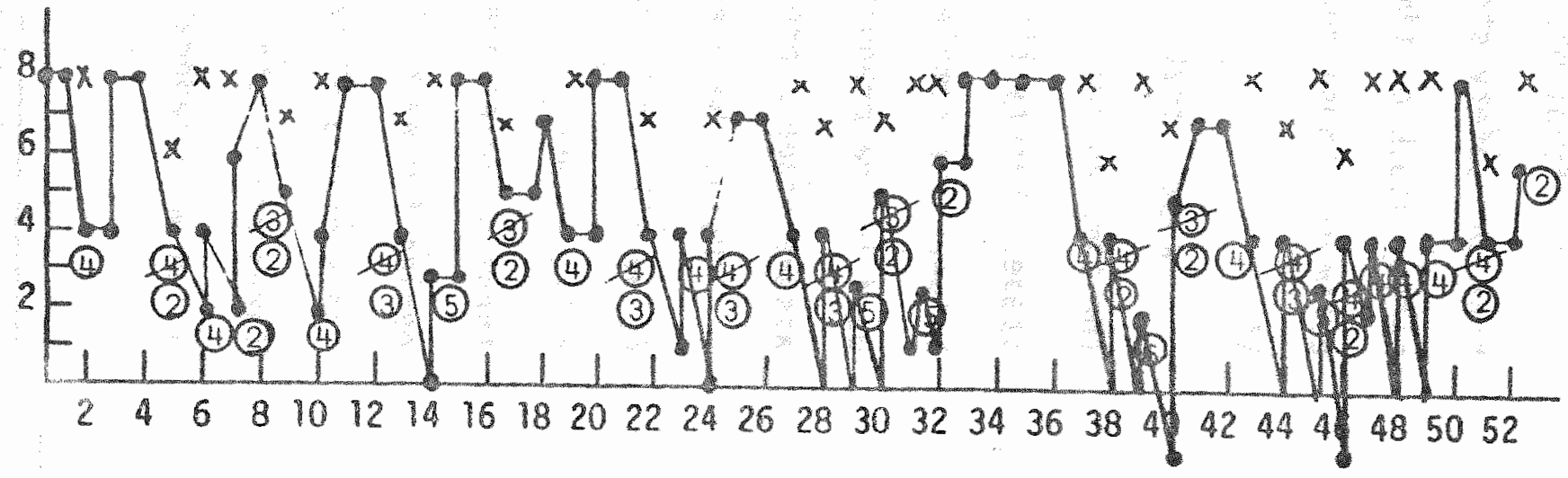

FIGURE 4. Graphs of Inventory Levels for 52 Periods for Problem 6 
The dots in Figure 4 a represent the on-hand installation stock for stage 2. Note that the graph indicates both beginning and ending inventory for each period. Asterisks indicate the stage's inventory position--on-hand plus on-order stock. The sane infomation is displayed for stage 1 in Figure 4c. In addition, the order quantities, desired and actual, are given for each order. As can be seen, although stage I's policy is a (7,8) policy, it: cannot always be implenented because the required anount of stock from stage 2 is not ay illable. The graph in Figure 40 shows the history of stage 2 's echelon stock.

We can make several observations from this sample realization. First, the average safety stock at stage 1 is 1.8 units. As can be seen from Figure $4 \mathrm{c}$, there is almost always on-hand inventory when a production lot is completed at stage 1. The average afety stock at stage 2 is 0 . The onhand inventory is zero before each order arrives. Thus there is no safety stock at stage 2. However, the safety time at stage 2 is 0.6 periods. This means that an order at stage 2 is avallable on the average 0.6 periods before it is used in a production at stage 1. As can be seen from Figure 4a, safety time exists during periods $18,25,26,33,34,35,36,41$ and 42 . Thus 9 periods of safery time exist for the 15 orders, or there are 0.6 periods of safety time per order on the average.

The following statistics can also be computed:

$\begin{array}{ll}\text { Average beginning onwand inventory at stage } 1 \text { is } 5.557 \text { units } \\ \text { Average beginning on-hand inventory at stage } 2 \text { is } 4.634 \text { units } \\ \text { Average ending on hand inventory at stage I } & \text { is } 3.538 \text { units } \\ \text { Average ending on-hand inventory at stage } 2 & \text { is } 2.615 \text { units } \\ \text { Average number of backorders (stage 1) } & \text { is } 0.3846 \text { units } \\ \text { Number of orders at stage ? } & \text { is } 31 \text { orders } \\ \text { Number of orders at stage } 2 & \text { is } 15 \text { orders } \\ \text { Average order quantity at i } & \text { is } 3.38709 \text { units } \\ \text { Average order quantity at } 2 & \text { is } 7.1333 \text { units } \\ \text { Fill rate } & \text { is } 0.98130 \\ \text { Service level (Ppobability of not running } & \text { is } 0.9615\end{array}$


To obtain reliable estimates of the above statistics for the problems in the experiment, we simulated the behavior of some of these systens for 7500 periods. Some of the results of the simulation runs are presented in Table XIII. We can make sone observations from these data.

\begin{tabular}{|c|c|c|c|c|c|c|}
\hline PROBLEM NO. & 5 & 13 & 14 & 17 & 18 & 19 \\
\hline Pollicy Stage 1 & $(6,7)$ & $(6.7)$ & $(7.8)$ & $(15,17)$ & $(18,19)$ & $(16,19)$ \\
\hline Pollcy stage 2 & $(8,12)$ & $(17,21)$ & $(20,24)$ & $(17,21)$ & $(19,23)$ & $(16,19)$ \\
\hline Safaty stock at I & 2.085 & 2.0286 & 2.3126 & 3.118 & $5.04 !$ & 2.305 \\
\hline Safety stock at $z$ & 0.155 & 1.278 & 2.0706 & 0.109 & 0 & 0 \\
\hline Safety Time & 0.135 & 0.2586 & 0.6050 & 0.1527 & 0.547 & 0 \\
\hline $\begin{array}{l}\text { Average order } \\
\text { quantity at } 1\end{array}$ & 2.597 & $\begin{array}{r}2.8303 \\
=\end{array}$ & 3.4227 & 3.301 & 3.679 & 9.724 \\
\hline $\begin{array}{l}\text { Average order } \\
\text { quantity at } 2\end{array}$ & 5.763 & 5.7541 & 6.8079 & 5.759 & 6.77 & 4.724 \\
\hline Fill rate & 0.977 & 0.967 & 0.9569 & 0.950 & 0.944 & 0.935 \\
\hline Service level & 0.964 & 0.9562 & 0.9512 & 0.955 & 0.914 & 0.932 \\
\hline
\end{tabular}

TABLE XIII. Results of Simulation Runs for Example Problems

If a collapsed policy is followed there is never any safety stock or safety time for stage 2 no matter what lead time structure exists. The results for problem 19 demonstrate this fact. The reason for this is that the policy paraneters are the same both stages. Consequently. as soon as the units becone avallable from stage 2 , the stage 1 policy indicates that production should comence immediately. We also observe that the only situations for which neither safety time nor safety stock exists at stage 2 is for problems in which a collapsed policy was followed. 
The lead time structure is also very important. Compare, for example, the results for problems 13 and 14 with those obtained for problems 17 and 18, respectively. Recall that the lead times are $\tau_{1}=1$ and $\tau_{2}=5$ for problems 13 and 14 and $\tau_{i}=5$ and $\tau_{2}=1$ for problems 17 and 18 . Observe that the safety stock is much higher when the lead times are longer. We note that demand variablity affects the anount of desired safety stock. This can be seen by comparing the results obtained for problem 13 with those found for problem 14, and those found for problem 17 with those of problen 18. The combined affect of long lead times and high demand variability will result in safety stock at a qiven stage.

Finally. we note that safety time exists at stage 2 for all cases except when a collapsed policy is followed. The mount of safety time depends on the length of the stage 2 lead time.-- 


\section{Y MRP POLICIES ARE $(S, S)$ POLICIES}

Our final comments are concerned with the form of the inventory policy corresponding to standard MRP logic. It is not hard to see that MRP policies are nothing more than (s,s) policies. This observation follows immediately from the manner in which planned production orders are triggered. Once echelon stock at a stage reaches a point corresponding to a predicted deficit at that stage at the end of the period a lead time in the future, an order is triggered. Thus the reorder point $s$ equals projected domand over a lead time plus one pertod, as given by the forecast, plus any bufper stocks required for that and succeeding stages. The order-up-to level $S$ depends on the lot sizing rule being followed. Our observation concerning the form of MRP policies does not depend on the lot sizing rule that is followed.

We will ilustrate these observations using an example. The cost and lead time data are given in Table xiv. The denand distribution used is Demand Distribution B in Table VIII. The optimal operating policy for this problem is $(7,8)$ polley at stage 1 and $2(9.13)$ policy at stage 2 . The probability of punning out of finished product during a period is .06 when following these policies. As a result, we define the service level for this system to be .94.

\begin{tabular}{c|rrrr} 
Stage & $k_{i}$ & $h_{i}$ & $p_{i}$ & $\tau_{i}$ \\
\hline 1 & 9 & 9 & 100 & 1 \\
2 & 30 & 5 & $\ldots$ & 1
\end{tabular}

TABLE XIV. Cost and Lead Tine Data for the Example Problen

Suppose Mrp loglc is used to detemine when orders are placed at each stage. Furchemome, assume a lot for-lot reorder size policy is followed. 
Recall that the forecasted demand for the finished product is 2 units in each period. Suppose that a. 94 service level is desirable. Then a safety stock, or buffer stock, of 4 units is required at stage 1. This quantity is computed based on the assumption that the production lead time is one period for stage 1 and no buffer stock is planned for stage 2.

To illustrate the behavior of the stock levels at each stage, we assume the demand pattern given in Table XII is experienced. We also assume the beginning on hand inventory at stage 1 is 8 units and at stage 2 is 6 units. No units are in production at either stage initially. We chose these starting values to illustrate that the long term system behavior when following a MRP policy is not affected by initial conditions. As we show, these starting values cannot be achieved if MRP ordering logic is followed.

The results of following MRP ordeng logic is shown in Table XV. For each stage and period we give forecasted demand, projected stock on-hand at the end of a period, net requirements, scheduled receipts, and planned orders. We also give the actual onhand stock at each stage at the beginning of each period both before and after the receipt of scheduled orders. The MRP systen operates on a rolling horizon basis. Data for the next 5 periods are given for each category for each period. The calculations are assumed to be made at the beginning of a period. After each period the appropriate adjustments are made to peflect the actual demand that has occurred. The numbers given in Table XV corpespond to the calculations nomally given when describing the behavior of a MRP system. They do not directly indicate the behavior of echelon stock, however. Graphs of echelon and stage stock levels for 8 periods are given in Figure 5. These graphs show that once the effects of the initial conditions are removed, the policy at stage 1 is a $(8,8)$ policy and at stage 2 is a $(10,10)$ policy, where the policy parameters are 


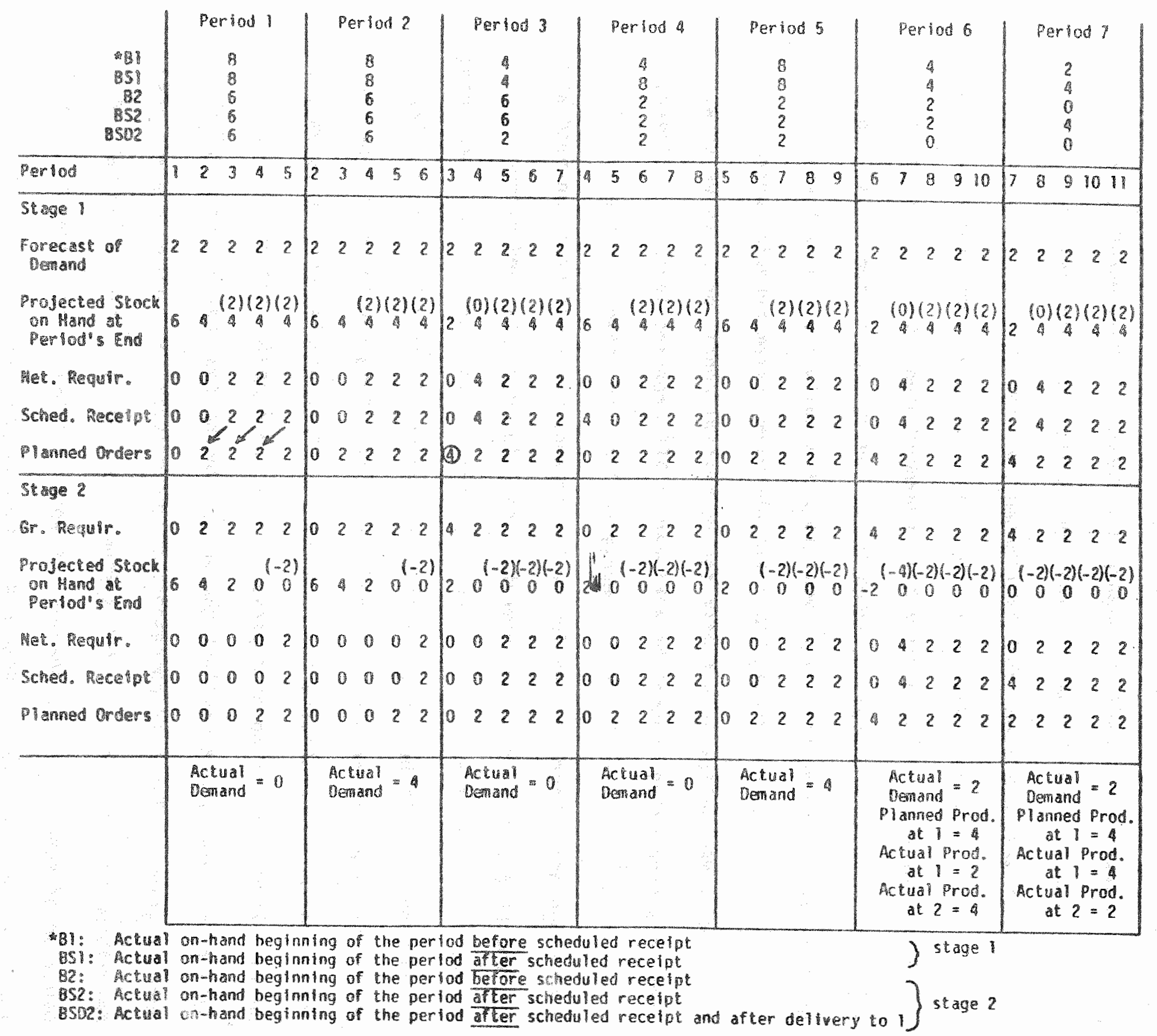

TABLE XV. KRP Schediles for The Example Problem 


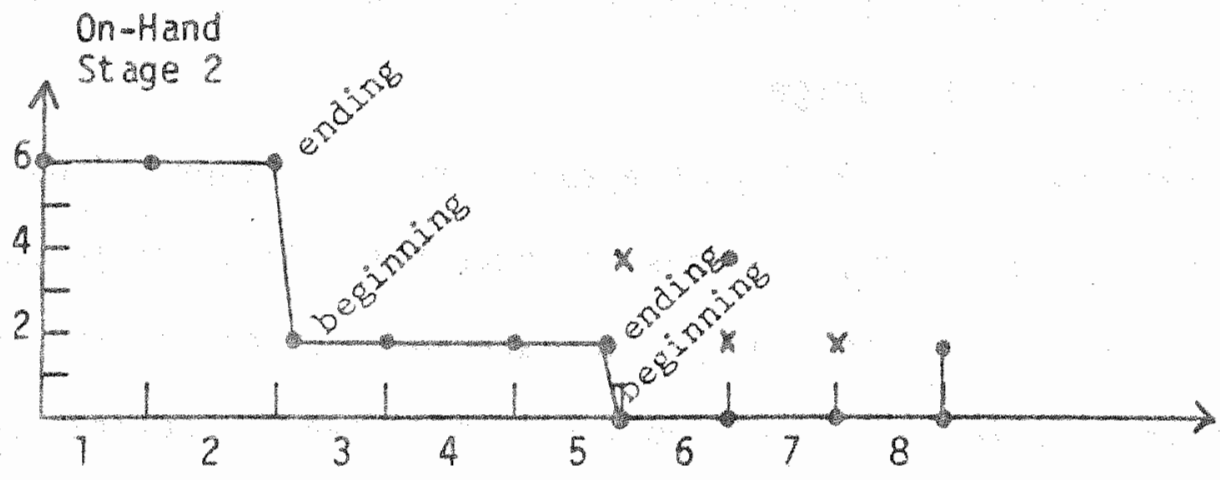

Echelon Stock

Stage 2

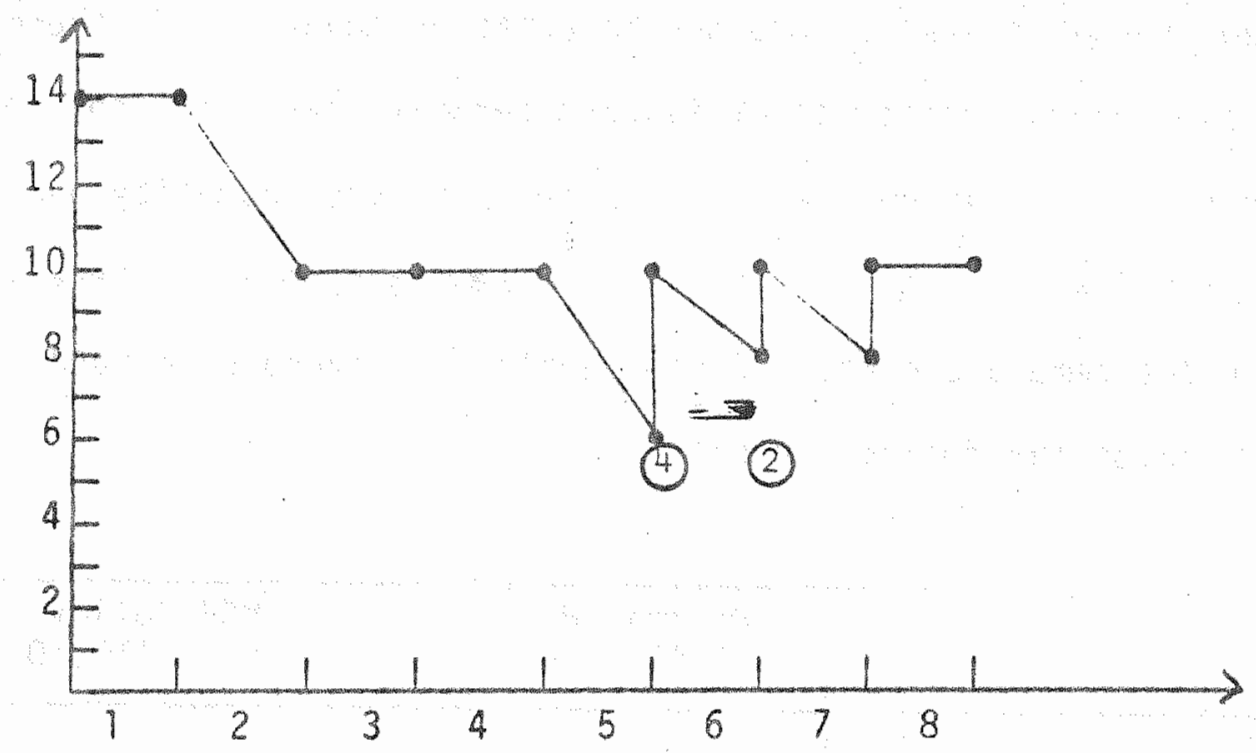

On-Hand

Stage 1

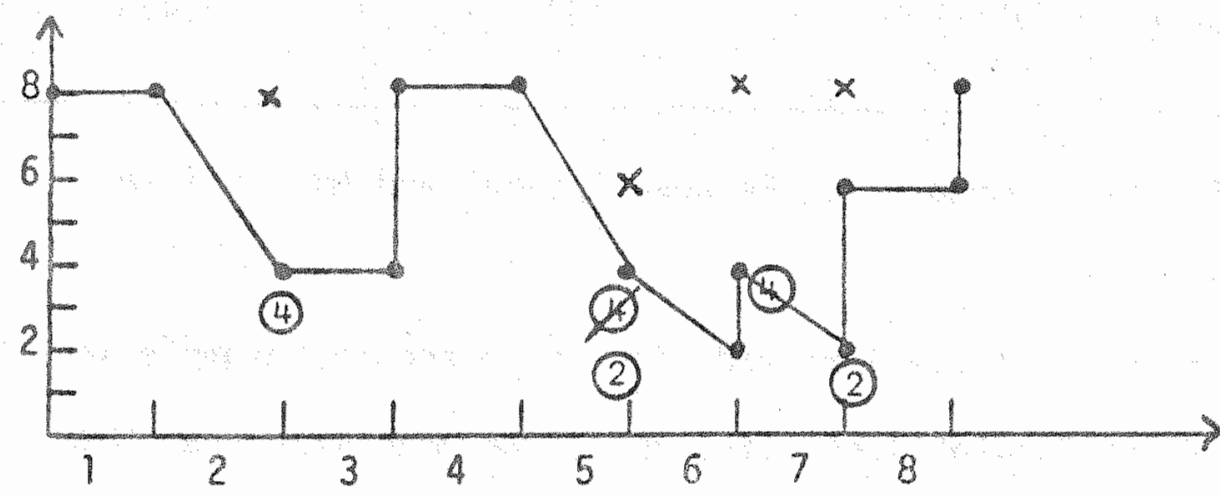

FIGURE 5. 
based on echelon stock. Thus the operating policy dictated by the MRP system is $(s, s)$ policy at each stage.

Recall that the optimal policy is also of the $(5,5)$ type. Thus the Mrp policy is of the correct form, but does not have the policy variables set at their optimal lavels. In this example, the average cost per period increases by about $7.4 \%$ when following the MRP policy rather than the optimal one. Some other statistical comparisons between the optimal and MRP policies are given in Table XVI. Observe that some safety time occurs as a result of the MRP logic even though it was not planned to exist in advance. Furthermore, observe that the average safety stock is considerably lower than the target value of 4 units. This happens because the desired order quantity and the actual production level at stage 1 are not the same and because there is variability in the demand process. Consequently, the average on hand inventory does reach the desired level.

\begin{tabular}{|l|c|c|}
\hline & $\begin{array}{c}\text { Optima l Policy } \\
(7,8),(9,13)\end{array}$ & $\begin{array}{c}\text { MRP Policy } \\
(8,8),(10,10)\end{array}$ \\
\hline Average safety stock at 1 & 2.029 & 2.2894 \\
Average safety stock at 2 & 0 & 0 \\
Safety time & 0.266 & 0.16 \\
Average order quantity 1 & 3.058 & 2.763 \\
Average order quantity 2 & 7.133 & 3.433 \\
\end{tabular}

TABLE XVI. Comparison Between optimal and MRP Policies

Recall that the calculations made for the preceding example were based on the use of a lot-for-lot scheduling rule. We emphasize that the conclusion we have reached concerning the form of MRP operating policies does not depend on this supposition. For example, if the Silver-Meal [12] 
heuristic is used to generate lot sizes, it is easy to show that the MRP policy is a $(8,8)$ policy at stage 1 and $a(10,12)$ policy at stage 2 . This policy was simulated for 9000 periods. Some comparisons between this and the optimal policy are given in Table XUII. Note that both safety time and stock exist at stage 2 when the Silver-Meal heuristic is used to determine lot sizes. We also observe that actual lot sizes and safety stock at stage 1 differ substantially from those that were planned.

\begin{tabular}{|l|c|c|}
\hline & $\begin{array}{c}\text { Optimal Policy } \\
(7,8),(9,73)\end{array}$ & $\begin{array}{c}\text { MRP (using Silver } \\
\text { Meal Method for } \\
\text { Lot Sizing) } \\
(8,8),(10,12)\end{array}$ \\
\hline Average Costs & $100 \%$ & \\
Average safety stock at 1 & 2.2048 & $102.57 \%$ \\
Average safety stock at 2 & 0 & 2.5929 \\
Safety time & 0.24 & 0.3295 \\
Average order quantity & 3.000 & 0.57 \\
Average order quantity 2 & 6.811 & 3.2144 \\
& & 3.8755 \\
\hline
\end{tabular}

TABLE XVII. Comparisons Between the optimal and MRP Policies

In sumary, MRP policies are $(s, s)$ policies. The values of the policy paraneters depend on the buffer stocks and lot sizing rules that are specified. Consequentiy, both safety stock and safety time can exist at intemediate stages, as we have shown with our example. The MRP policies generally appear to be of the optimal or nearly optimal form, but normally will not have the policy variables set at optimal values. As long as demand varlability is relatively low over the lead time. $\tau_{1}+\tau_{2}$, the MRP policies wll be close to optimal, in a cost sense. However, when lead times are long and demand variability is high, then MRP poficles can perfom very poorly. Thus it is important in these cases to use better heuristics, such as the MCS heuristic, to determine good operating policy. 


\section{REFERENCES}

[1] ARROH, K.J., S. KARLIN, and H. SCARF, Studies in the Mathenatical Theory of Inventory and Production, Stanford University Press, Stanford Calfornta, 1958.

[2] BANERJEE, A., Buffer Inventories for Material Requirements Planning Systens, "Working Paper University of Delaware, May 1978.

[3] CARLSON, R. and A. YANO, "Buffering Against Demand Uncertainty in Material Requirenents PI anning Systems - Systems with no Emergency Setups," Technical Report 4 1-2, Department of Industrial Engineering and Engineering Management, Stanford University, April 1981, p. 29.

[4] CARLSON, R. and A. YANO, "Buffering Against Demand Uncertainty in Material Requirements Planning Systems - Systems with Emergency Setups for Some Components, Technical Report \#81-3, Department of Industrial Engineering and Engineering Management, Stanford University, April 1981, p. 27 .

[5] CLARK, A. and H. SCARF, "optimal Policies for a Multi-Echelon Inventory problem, Management Science, Vol. 6. No. 4. July 1960, 474-490.

[6] CLARK, A. and H. SCARF, Approximate Solutions to a Simple Multi-Echelon Inventory Problem," Chapter 5 in K. Arrow. S. Karlin and H. Scarf (Eds.). Studies in Applied Probatid ity and Management Science, Stanford University Press, Stantord, Catifornia, 1962.

[7] HOWARD, R. Dynamic Programing and Markov Processes, M. I.T. Press, Cambridge, Massachusetts, 1960.

[8] MAXWELL, W. and MUCKSTADT, J., "Establishing Reorder Intervals in Multi-Stage Production-Distribution Systems," Technical Report \#561, School of Operations Research and Industrial Engineering, Cornell University, Ithaca, NY, 1982.

[9] MEAL, H.C., "Safety Stocks in MRP Systems," Technical Report $\# 166$. Operations Research Center, Massachusetts Institute of Technology. Cambridge, Massachusetts.

[10] MILLER, J., "Hedging the Master Schedule," in Disaggregation Problems in Manufacturing and Service Organizations, Eds. L. Ritzan et a.,. Martinus NiJhof PubT. Company. 1979, $237-256$.

[11] NEW, C. "Safety Stocks for Requirements Planning" Production and Inventory Managenent, 2nd, Qtr. 1975, 1-18.

[12] SILVER, E. and MEAL, H. M Heuristic for selecting Lot-size Quantities for the Case of a Deterministic Time-varying Denand Rate and Discrete opportunities for Replenishment," Production and Inventory Managenent. Vol. 14, No. 2, 1973, pp. 64-74.

[13] WHYBARK, C. and J. WILLIAMS, Material Requirements planning under Uncertainty." Deciston Sciences, Vol. 7, No. 4, 1976, 595-606. 